\title{
A review of breast cancer aspects and its diagnosis by MRI
}

Mateus A Gonçalves ${ }^{1}$, Bruna T L Pereira ${ }^{1}$, Camila Assis Tavares ${ }^{1}$, Taináh Martins ${ }^{1}$, Elaine F F Da Cunha ${ }^{1}$, and Teodorico C Ramalho ${ }^{1}$

${ }^{1}$ Department of Chemistry, Federal University of Lavras

June 2, 2021

\section{Hosted file}

cancer_final (3).pdf available at https://authorea.com/users/417415/articles/524536-a-reviewof-breast-cancer-aspects-and-its-diagnosis-by-mri 